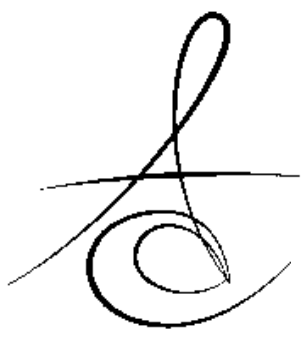

\section{İMPLANT ABUTMENT VİDA KIRIKLARININ DENTAL OPERASYON MİKROSKOBU KULLANILARAK ÇIKARTILMASI: TEKNİK TANITIM ${ }^{\neq}$}

\section{REMOVAL OF FRACTURED IMPLANT ABUTMENT SCREWS USING DENTAL OPERATING MICROSCOPE: TECHNICAL REPORT ${ }^{\neq}$}

\author{
Yrd.Doç.Dr.Serdar POLAT* Arş.Grv.Dr. Emre TOKAR* \\ Prof.Dr.Özgür UZUN**
}

Makale Kodu/Article code: 2723

Makale Gönderilme tarihi: 28.03.2016

Kabul Tarihi: 27.04 .2016

\section{öz}

Eksik dişlerin restorasyonunda dental implantlar başarıyla kullanılmaktadır. Ancak, implantlar abutment vida kırı̆ı durumunda kullanılamaz hale gelmektedir. Kırık vida parçasının implant vida deliğinden çıkarılması, vida kırığı boyun ve yiv bölgesinde olduğu durumlarda çok güçtür. Kırık vidanın direk olarak izlenememesi ve kırık parçaya kısıtlı açıklıktan ulaşılması klinisyenler için ciddi bir problem teşkil etmektedir. Bu teknik tanıtımda kırık vida parçalarının dental operasyon mikroskobu kullanılarak çıkarılması işlemi anlatılmıştır.

Anahtar Kelimeler: İmplant kırığı, kırık vida çıkarılması, dental operasyon mikroskobu, teknik

\section{GİRIŞ}

Diş kayıplarının tedavilerinde implant restorasyonları günümüzde sıklıkla kullanılan tedavi seçenekleridir. İmplant tedavilerinde yüksek başarı oranı ve kolay uygulanabilirliklere rağmen mekanik, teknik ve biyolojik komplikasyonlar meydana gelebilmektedir. ${ }^{1-2}$ En ileri seviyedeki komplikasyon implantların kaybıdır. Dental implant kayıpları implant restorasyonu veya periimplantitis kaynaklıdır. İmplant restorasyonlarının sebep olduğu komplikasyonlar teknik problemlerdir ve bunlar implant parçaları ve protezin sebep olduğu problemler olarak değerlendirilebilir. ${ }^{3}$

İmplant komponentlerinde görülen teknik komplikasyonlar implant kırığı, abutment kırı̆ı, protez kırığı,

\section{ABSTRACT}

Dental implants are successfully used to restore missing teeth. But the implants may be got useless in case of fracture of abutment screw. Removal of the fractured screw fragment from the screw hole can be challenging when fracture line is at the screw shank or screw thread. Unable to direct vision of the fractured screw and limited access to fractured component can be a serious problem for clinicians. The procedure used for removal of the fractured screw fragments using dental operating microscope is described in this technical report.

Keywords: Implant fracture, removal of fractured screw, dental operating microscope, technique abutment vidasının gevşemesi veya kırığıdır. ${ }^{2,4-5}$ Tespit edilemeyen vida gevşemesi, bruksizm, uygun olmayan üst yapı, aşırı yükleme veya malfonksiyon, hatalı biyomekanik yük dağılımı, tekrarlayan vida gevşemesi ve sıkılması, protezin pasif oturmaması, üretim hataları vida kırıklarının primer sebepleridir. ${ }^{3,6-12}$

Vida kırıklarıyla karşılaşıldığı zaman implantı yeniden kullanabilmek çok kolay olmamaktadır. Vida kırığıyla karşılaşılan durumlarda aşağıdaki yöntemlerin uygulandığı literatürde belirtilmiştir. ${ }^{4,13-14}$

-Arter forsepsi tekniği

-Ultrasonik scaler

-Lubrikant tekniği

-Düşük hız ters açı frez tekniği

-Tamir veya çıkarma kiti

-Vidayı aşındırarak küçültme tekniği

\footnotetext{
${ }^{*}$ Gazi Üniversitesi, Diş Hekimliği Fakültesi, Protetik Diş Tedavisi AD.

${ }^{* *}$ Gazi Üniversitesi, Diş Hekimliği Fakültesi, Endodontik Diş Tedavisi AD.

₹5.Uluslararası Türk Prostodonti ve İmplantoloji Derneği Bilimsel Sempozyumunda

poster olarak sunulmuştur. Poster No: -P.201646 - 18-20 Mart 2016, Erzurum
} 
Vida kırıklarındaki en büyük zorluk bölgenin direk görüntülenememesi ve küçük bir alanda çalışılmasıdır. Dental pratikte görülebilmesi zor olan alanlarda işlem yapabilmek için son dönemde büyütme gözlükleri ve mikroskoplar kullanılmaktadır.

Dental operasyon mikroskopu (DOM) farklı büyütme ve güçlü aydınlatması ile diş hekimliği uygulamalarında ayrıntılı görüş sağlayan bir cihazdır. DOM cihazı içerisinde bulunan mercek sistemleri sayesinde operasyon alanının görüntüsünü farklı derecelerde büyütebilmekte, cihaza entegre, Halojen, Zenon yada LED aydınlatma sistemleri ile de bölgenin kuvvetli bir şekilde aydınlatılabilmesini sağlamaktadır. Diş hekimliğinde farklı alanlarda uygulama yeri bulan cihaz özellikle Endodontik işlemlerde vazgeçilmez cihazlardan biridir.

Cihazın aydınlatma ve büyütme alanı yeterliliği, kırık abutment vidalarının görülebilmesindeki güçlüğü ortadan kaldırabilmektedir. Gerekli izolasyonlar yapıldıktan sonra DOM ile kııı parçanın bulunduğu implanta bakıldığında, kırık parça net olarak görülebilmekte ve uygun yöntemle çıkarılabilmesi mümkün olmaktadir. $^{15}$

Bu raporda DOM kullanılarak kırık abutment vidalarının 3 vakada çıkartıması anlatılmışır.

\section{TEKNİK TANITIM}

Olgu 1; 44 yaşındaki erkek hastanın mandibular sol alt 1. büyükazı bölgesine 5 yıl önce IDI (IDI, Paris, Fransa) marka implant yapılmıştır. Hasta o tarihten itibaren dişinde mobilite hissettiğini ifade etmiştir. Hasta kırılan implant üstü protezi ile birlikte kliniğimize başvurmuştur. Radyografik inceleme neticesinde abutment vida kııı̆ı gözlenmiştir (Şekil 1)

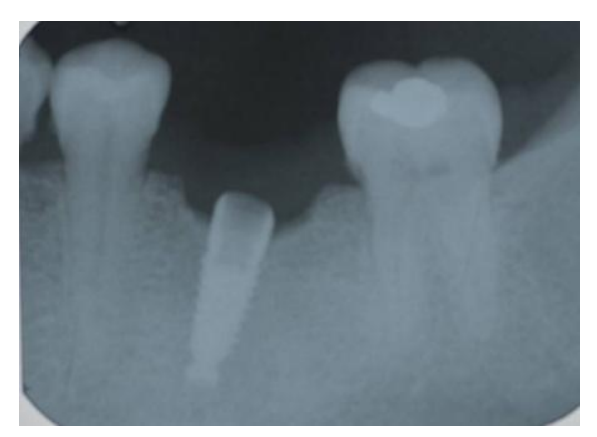

Şekil 1. Abutment vidası kırılmış implant

Olgu 2; 52 yaşındaki bayan hasta sağ alt 1 . büyükazı bölgesine bölgesine 7 yıl önce Straumann
(Straumann, Basel, İsviçre) marka implant yapılmışır. Kullanım süresince hasta herhangi bir problem yaşamamış olmasına rağmen implantının kırıldığını ifade ederek kliniğimize başvurmuştur. Radyografik inceleme neticesinde abutment vida kırığı tespit edilmiştir (Şekil 2)

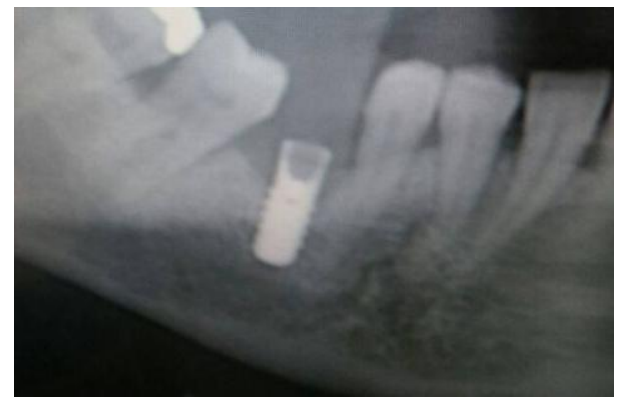

Şekil 2. Abutment vidası kırılmış implant

Olgu 3; 55 yaşındaki erkek hastanın üst çenesine 1 yll önce 4 adet Astra Tech(Dentsply, Mannheim, Almanya) implant yerleştirilmiş ve bu implantların üzerine implant destekli locator tutuculu overdenture protez yapılmıştır. Hasta kliniğe abutmentin düştüğünü belirterek başvurmuştur. Yapılan klinik ve radyografik inceleme sonucunda sol üst 1 . küçükazı bölgesine numaralı diş bölgesindeki locator tutucunun vidasının kırıldığı gözlenmiştir (Şekil 3)

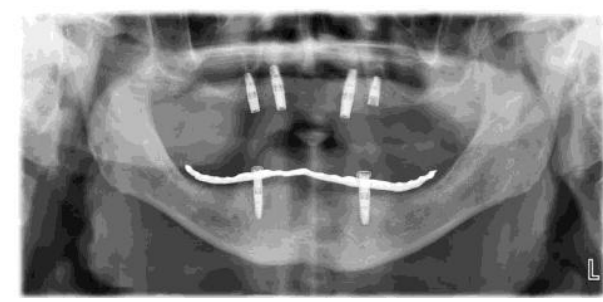

Şekil 3. Abutment vidası kırılmış implant

Kliniğimize abutment vida kırığı sebebi ile başvuran hastalara vidaların çıkartılması için standart tedavi protokolü uygulanmıştır. Bu protokolde;

1- Hastaların implant bölgeleri izole edildi. İmplantların üzerini örterek görüşü engelleyen diş eti dokusu uzaklaştırıldı veya dekole edildi.

2- Kırık parcayı içeren implant DOM (Zeiss, Oberkochen, Almanya) (x 8 ve $\times 12.5$ büyütme seviyeleri kullanılarak) ile incelenerek kullanılacak kırık parça lokalize edilip, ayrıntılı görüş sağlandı. Kırık parçanın yüzeyinde kuvvet uygulanabilecek destek yüzeyleri incelendi. (Şekil 4)

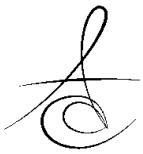




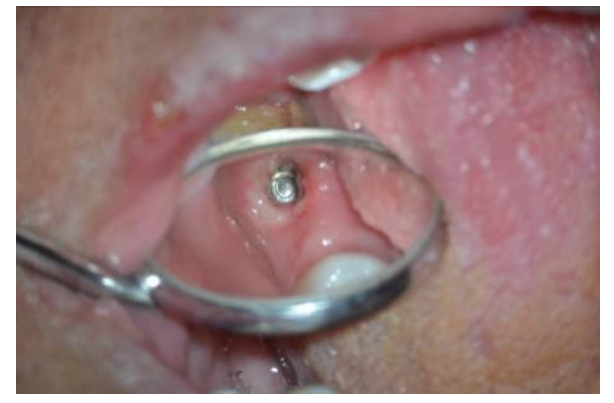

Şekil 4. Kırık vidanın DOM ile alınan görüntüsü

3- Destek yüzey belirgin olduğu durumlarda direk bu yüzeye sonik kazıyıc temas ettirilerek vidanın çıkartılma yönünde sonik titreşim verildi. Sonik scalerın ucunun destek alamadığı durumlarda ince sond veya el aletleri ile temas sağlandıktan sonra el aletlerine ultrasonik aletin titreşimi verilerek vidanın gevşemesi sağlandı. Vida implant içerisinde yükseldikten sonra çıkartıldı. (Şekil 5)

$\mathrm{Bu}$ işlemler hastanın kooperasyonuna ve implantın bulunduğu bölgeye göre 1 dakika ile 6 dakika arasında tamamlandı. Sonik enerji sonucunda oluşan ısıya bağlı hasarları önlemek için, sonik uygulamada su sprey seviyesi orta ve üst seviyelere ayarlandı ve işlemler su spreyi altında yapıldı.

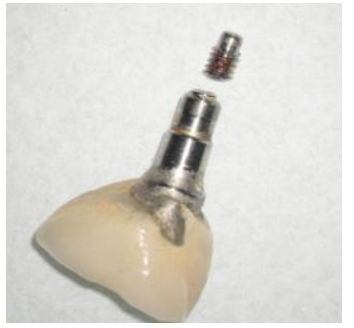

Şekil 5. İmplant içerisinden çıkartılmış kırık vida parçası ve implant-üstü kron

\section{TARTIŞMA}

İmplant komponentlerinde görülen komplikasyonların bazıları iç yapı kaynaklıdır. Kırık vidanın implant iç yüzeyine zarar verilmeden çıkartılması klinik açıdan büyük zorluk arz etmektedir. ${ }^{16} \mathrm{Bu}$ nedenle literatürde pek çok farklı yöntem belirtilmiştir ${ }^{4,13-14}$ ve implant üreticilerine ait pek çok vida çıkarma seti kullanılabilmektedir. ${ }^{17}$

Bu yöntem ve setlerin kullanımı zaman tüketimi açısından uygun değildir, bununla birlikte bu işlemler implant iç yüzeyine zarar verebilmektedir. Özel setler kompleks ve zor olabilmektedir. ${ }^{3}$ Bu özel setleri kullanarak yapılan işlemlerde başarı ile ilgili tahmin yapmak güçtür ve başarı olguya özeldir, her vaka için başarılı sonuçlara ulaşılamayabilir. ${ }^{3,17}$

Sunulan teknikte DOM kullanımı ile işlem doğrudan gözlendiği için amaçlanan bölgeye müdahale edilmiştir. Bu şekilde yöntemin etkinliği artmakla beraber hasta başında harcanan süre diğer yöntemlere göre oldukça azalmıştır. Direk müdahale ile implant iç yüzeyine zarar verme riski de minimuma indirilmiştir. Yöntemde kullanılan sonik sistemin soğutma etkinliği implant ve çevre dokularda ISı oluşumuna engel olmaktadır ve ısının verebileceği zarar ortadan kalkmıştır. Flep kaldırmanın gerekli olmaması, anestezi uygulanmadan yapılması, her implant sistemine uygulanabilir olması yöntemin diğer avantajlarıdır. DOM'un ekonomik olmaması yöntemle ilgili dezavantaj olarak gösterilebilir.

\section{KAYNAKLAR}

1-Ekelund JA, Lindquist LW, Carlsson GE, Jemt T. Implant treatment in the edentulous mandible: a prospective study on Branemark system implants over more than 20 years. Int J Prosthodont. 2003;16:602-8.

2-Goodacre CJ, Kan JY, Rungcharassaeng K. Clinical complications of osseointegrated implants. J Prosthet Dent. 1999;81:537-52.

3-Nergiz I, Schmage P, Shahin R. Removal of a fractured implant abutment screw: a clinical report. J Prosthet Dent. 2004;91:513-7.

4-Gupta S, Gupta H, Tandan A. Technical complications of implant-causes and management: A comprehensive review. Natl J Maxillofac Surg. 2015;6:3-8.

5-Ezirganlı S, Sarı F, Köşger HH. Osseointegre Dental İmplant Kırığının Değerlendirilmesi: Olgu Sunumu. Atatürk Üniv Diş Hek Fak Derg. 2012;22:168-71.

6-Green NT, Machtei EE, Horwitz J, Peled M. Fracture of dental implants: literature review and report of a case. Implant Dent 2002;11:137-43.

7-Taylor TD, Agar JR, Vogiatzi T. Implant prosthodontics: current perspective and future directions. Int $\mathrm{J}$ Oral Maxillofac Implants 2000;15:66-75.

8-Eckert SE, Meraw SJ, Cal E, Ow RK. Analysis of incidence and associated factors with fractured 
implants: a retrospective study. Int J Oral Maxillofac Implants 2000;15:662-7.

9-Bakaeen LG, Winkler S, Neff PA. The effect of implant diameter, restoration design, and occlusal table variations on screw loosening of posterior single-tooth implant restorations. J Oral Implantol 2001;27:63-72.

10-Fard AM, Jacobs LC. Retrieval of a stripped abutment screw: a clinical report. J Prosthet Dent. 2010;104:212-5.

11-Williamson RT, Robinson FG. Retrieval technique for fractured implant screws. J Prosthet Dent. 2001;86:549-50.

12-Satterthwaite J, Rickman L. Retrieval of a fractured abutment screw thread from an implant: a case report. Br Dent J. 2008;204:177-80.

13- Reyhanian A, Parker S, Moshonov J, Fuhrman N. The use of Er: YAG in laser-assisted broken abutment screw treatment. Case report. Er: YAG. Lasers. 2010;3:6-11.

14- Pow EH, Leung KC. Prosthodontic complications in dental implant therapy. Hong Kong Dent J. 2008;5:79-83.

15-Uzun O, Yalpı F. Endodontide Büyütme Ve Aydinlatma. GÜ Diş Hek Fak Derg 2012;29:51-61.

16-Bhandari S, Aggarwal N, Bakshi S. Ultrasonic oscillations for conservative retrieval of a rare fracture of implant healing abutment. J Oral Implantol. 2013;39:475-8

17- Walia MS, Arora S, Luthra R, Walia PK. Removal of fractured dental implant screw using a new technique: a case report. J Oral Implantol. 2012;38:747-50.

\author{
Yazışma Adresi \\ Yrd.Doc.Dr.Serdar Polat, \\ Gazi Üniversitesi Diş Hekimliği Fakültesi \\ Protetik Diş Tedavisi Anabilim Dalı \\ Bişkek Cd.(8.Cd.) 82.Sk. No:4 \\ 06510 Emek - ANKARA \\ e-mail: drserdarpolat@gmail.com
}

